\title{
A NEW METHOD OF PREPARING A ROTATING RING-DISC ELECTRODE FOR THE STUDY OF CARBON SUPPORTED CATALYSTS
}

\author{
A. VAN DER PUTTEN, W. VISSCHER and E. BARENDRECHT \\ Laboratory for Electrochemistry, Department of Chemistry, Eindhoven University of Technology, \\ P.O. Box 513, 5600 MB Eindhoven (The Netherlands)
}

(Received 2nd January 1985; accepted 5th June 1985)

\begin{abstract}
A new preparation method is described for the study of carbon supported electrodes, which are currently under investigation for fuel cell applications. The carbon is applied to the disc of a rotating ring-disc electrode (RRDE) through incorporation of the carbon particles in a polypyrrole film. Electron transport to the carbon is possible because the polypyrrole is electronically conducting; the high porosity of the film enables the diffusion of reactants into the pores of the catalyst. This new technique offers an easy and quick way of measuring both the activity and selectivity of carbon supported catalysts.
\end{abstract}

\section{INTRODUCTION}

In order to produce fuel cell electrodes with a very high surface area, suitable catalysts are dispersed on carbon, mixed with a binder such as Teflon, and pressed onto a metal screen [1] to form a gas diffusion electrode. The electrocatalytic properties of such electrodes are determined by recording their voltammetric behaviour. This method, however, has some disadvantages. Firstly, the transport of the fuel and the oxygen is very ill-defined: the $i-E$ curve is determined by the electrocatalytic as well as the microgeometric properties determining transport of the electrode, and is therefore not a good measure for the catalytic properties as such. Secondly, these measurements do not provide any information about the selectivity of the electrode reactions. Information of this kind can be obtained with more sophisticated hydrodynamic methods, such as with the RRDE. Therefore, it would be convenient if the carbon supported catalyst could be applied as a very thin layer to the disc of such an electrode. This modified electrode has to fulfil a number of conditions:

(1) the layer must be very thin so that the hydrodynamic behaviour of the RRDE is not disturbed;

(2) the layer must be accessible to electrons and reactants (the use of paste electrodes is less appropriate since the pasting liquid causes wetting problems of the catalyst [2]).

Another way of manufacturing such an electrode, without the use of a pasting liquid, is by electrophoretic deposition, as described by Savy et al. [3], but we were 
unable to reproduce their results. The distribution and adherence of the carbon to the disc appeared to be insufficient. Therefore, we investigated the possibility of incorporating the carbon in a polymeric film [4]. Polypyrrole was chosen since we already had some experience in preparing this polymer. Moreover, it satisfies the conditions of conductivity and high porosity.

\section{PREPARATION TECHNIQUE}

Polypyrrole (PP) can be deposited at an electrode by electropolymerization of

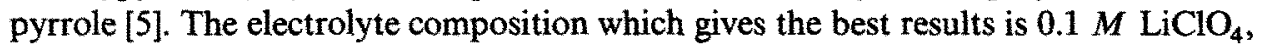
1 vol.\% pyrrole, in acetonitrile; (however, other solvents, e.g. water, can also be used). Polymeric units are formed according to:

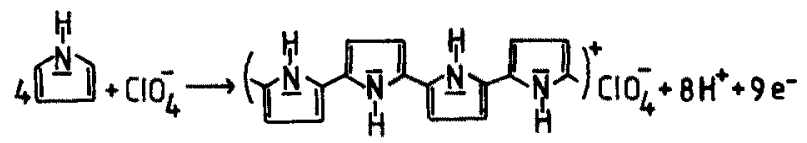

The polymer itself is electroactive. In the potential range of interest for fuel cell reactions ( $0-1 \mathrm{~V}$ vs. $\mathrm{RHE}$ ), the polymer is in the oxidized, conducting state. The stability is good in acidic solutions but in alkaline solution it is too low to perform reliable experiments. To prepare the carbon modified electrodes, suspensions of carbon (Norit BRX) of different concentrations ( $250-1250 \mathrm{mg} / \mathrm{l}$ formation solution) were made. As a carrier RDE, we used one with an Au disc $\left(0.5 \mathrm{~cm}^{2}\right)$ and a Pt-ring $(N=0.27)$. First, the following technique was tried. The electrode was rotated (faced down) in the carbon suspension. (Rotation was necessary since the suspensions are unstable due to coagulation of the carbon particles.) Rotation of the RRDE not only causes a flow in the electrolyte which keeps the particles in solution, but also constantly supplies particles to the disc of the RRDE. PP was formed potentiostatically at ca. $800 \mathrm{mV}$ vs. a saturated calomel electrode (SCE). The counter-electrode was a platinum foil. The amount of polymer and the rate of its formation were monitored by recording the amount of charge that passed through the circuit, $24 \mathrm{mC}$ $\mathrm{cm}^{-2}$ being equivalent to $0.1 \mu \mathrm{m}$ PP [6]. After the formation, the electrode was flushed with ethanol, dried and inspected microscopically. This method gave irreproducible results: virtually no carbon was incorporated in the PP film. The addition of a surfactant to the electrolyte $\left(10^{-3} \mathrm{M}\right.$ sodium toluene sulphonate) to charge the carbon particles negatively so that they could be incorporated as large anions did not give any improvement. Hence, the following technique was developed.

On top of the RRDE (faced upwards!) a tight-fitting KEL F hood was placed in which a hole was drilled with exactly the same diameter as the disc (Fig. 1). This cell was filled with $500 \mu 1$ carbon/electrolyte/monomer suspension, which had previously been agitated in an ultrasonic bath for $5 \mathrm{~min}$. A cylindrical Pt electrode was placed in the convex meniscus at the top of the cell. In the cell, the carbon particles precipitate on the disc surface. When the current is switched on, polymerization of the pyrrole starts both on the gold electrode and the carbon. The polymer chains 


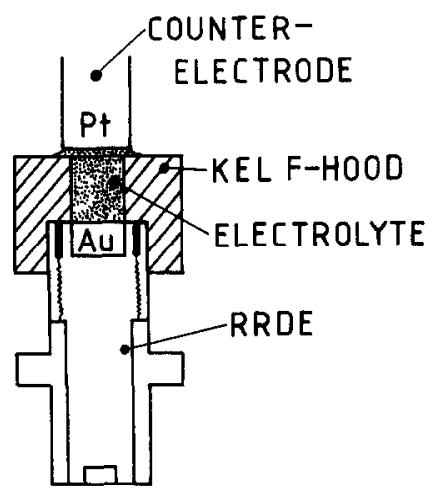

Fig. 1. Cross-section of the electrochemical cell.

grow into a three-dimensional network which attaches the carbon to the electrode. Visual inspection after flushing with ethanol and drying showed that indeed the carbon was incorporated in the polymer film. The adherence of the particles and the stability of the film were good enough to perform RRDE experiments. Although the distribution of the carbon over the disc surface was very fine and regular, some spots on the surface were only covered with PP. More concentrated suspensions resulted in irregular deposits. The use of acetylene black, which has a smaller particle size than Norit BRX, did not give any improvement since it formed aggregates on a very short time scale, also resulting in irregular deposits.

The best results were obtained with a Norit BRX suspension of $500 \mathrm{mg}^{-1}$, and PP formation for $10 \mathrm{~min}$ with a current of $1 \mathrm{~mA}$.

\section{THE HYDRODYNAMIC BEHAVIOUR}

The introduction of carbon particles in a PP layer results in an electrode with a certain surface roughness, which will influence the hydrodynamic behaviour of the RRDE. Especially at high rotation frequencies, the thickness of the diffusion layer will become of the same order of magnitude as the surface roughness, resulting in deviations of the equations derived by Levich [7]; the effective surface for the diffusion becomes larger than the geometric one. This effect was verified in a $5 \times 10^{-2} M \mathrm{~K}_{3} \mathrm{Fe}(\mathrm{CN})_{6}$ solution in $1 \mathrm{M} \mathrm{KCl}$. The disc current was measured at $-200 \mathrm{mV}$ (vs. SCE), where the reduction of the ferri-complex is diffusion-limited; the ring was held at $+800 \mathrm{mV}$ (vs. SCE). The reduction of ferricyanide also proceeds at the PP itself. The results of the disc current and the calculated collection efficiency $\left(-I_{\mathrm{R}} / I_{\mathrm{D}}\right)$ as a function of the rotation frequency are presented in Fig. 2 . The dashed lines represent the theoretical values for $I_{\mathrm{D}}$ and $N$ according to the equations of Levich and of Albery and Bruckenstein, respectively.

From Fig. 2 it follows that such behaviour is obeyed up to a rotation frequency of 


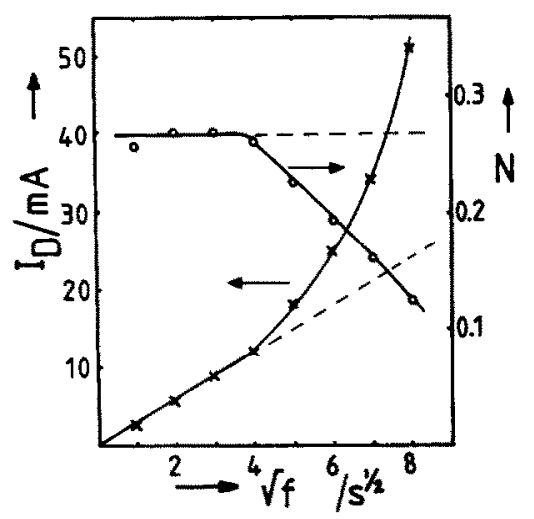

Fig. 2. Limiting disc current $(X)$ and measured collection efficiency $(O)$ of the reduction of ferricyanide $\left(5 \times 10^{-2} M\right)$ at a carbon modified electrode, as a function of the square root of the rotation frequency. The dashed lines represent the values corresponding to the Levich equations.

$16 \mathrm{~s}^{-1}$. At higher frequencies the disc current deviates in the positive direction, as expected; the measured collection efficiency then decreases.

Therefore, our experiments were carried out in the frequency range of $0-16 \mathrm{~s}^{-1}$.

\section{RESULTS OF SOME PRELIMINARY EXPERIMENTS}

In order to show the possibilities of this new method, oxygen reduction was studied in $0.5 \mathrm{M} \mathrm{H}_{2} \mathrm{SO}_{4}$ at electrodes with four different types of carbon: Norit BRX $(0.2 \mathrm{mg})$ and Norit BRX, impregnated with $20 \mathrm{wt} \%$ metal free, cobalt- and iron phthalocyanine, respectively $\left(\mathrm{H}_{2} \mathrm{Pc}, \mathrm{CoPc}\right.$ and $\left.\mathrm{FePc}, 0.25 \mathrm{mg}\right)$. The impregnation was carried out by dissolving $10 \mathrm{mg}$ of the corresponding Pc in $20 \mathrm{ml} \mathrm{THF}$, adding $40 \mathrm{mg}$ Norit BRX, and refluxing and stirring for $30 \mathrm{~min}$. Thereafter, an equal volume of water was added, the carbon filtered (G4 glass filter), washed with water and ethanol, dried at $100^{\circ} \mathrm{C}$ and ground for $5 \mathrm{~min}$ in an agate mortar.

The results with these electrodes can be compared with those obtained at gas diffusion electrodes [8]. The reduction of oxygen can proceed along two pathways: the direct reduction to water, and the reduction to hydrogen peroxide, which can subsequently be reduced to water.

The ring electrode was slightly platinized to ensure quantitative detection of hydrogen peroxide. This was done before the modification of the disc to avoid platinum adsorption on the carbon. After the modification, the electrode was transferred to $\mathrm{O}_{2}$-saturated $0.5 \mathrm{M} \mathrm{H}_{2} \mathrm{SO}_{4}$. After activation of the ring by periodical evolution of $\mathrm{H}_{2}$ and $\mathrm{O}_{2}$ for $1 \mathrm{~min}$, the net oxygen reduction current was measured at a rotation frequency of $9 \mathrm{~s}^{-1}$. The disc potential was varied from +1000 to +200 $\mathrm{mV}$ (vs. RHE). At the ring $\left(+1200^{\circ} \mathrm{mV}\right.$ vs. RHE) the peroxide production was monitored. All measurements were performed at room temperature.

Figure 3 gives a characterization of the disc electrode. The dotted curve represents 


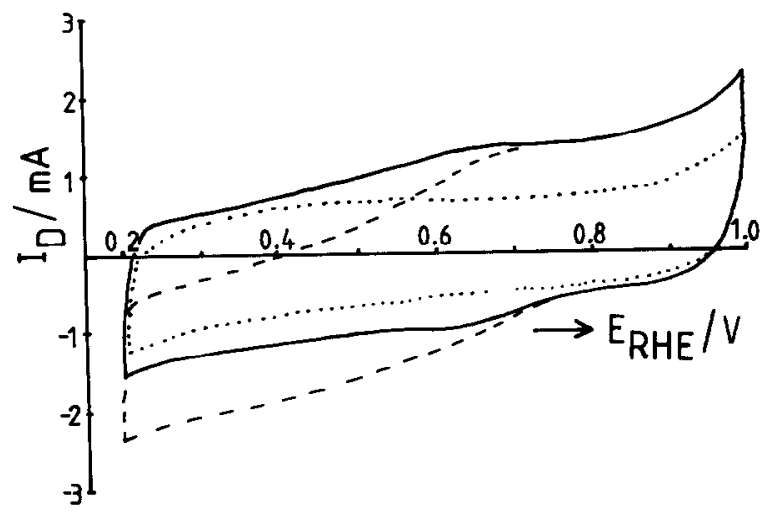

Fig. 3. Cyclic voltammetric characterization in $0.5 \mathrm{M} \mathrm{H}_{2} \mathrm{SO}_{4}$ of a $600 \mathrm{mC}$ PP film on gold ( $\left.\cdots \cdots\right)$, a 20 wt\% FePc/Norit BRX modified stagnant PP electrode in $\mathrm{N}_{2}$ saturated solution $(-\longrightarrow)$, and in $\mathrm{O}_{2}$-saturated solution at $f=9 \mathrm{~s}^{-1}(---)$. Scan rate $=10 \mathrm{mV} \mathrm{s}^{-1}$; disc surface $=0.5 \mathrm{~cm}^{2}$.

a gold electrode in an oxygen-free $0.5 \mathrm{M} \mathrm{H}_{2} \mathrm{SO}_{4}$ solution, covered with $600 \mathrm{mC} \mathrm{PP,}$ without carbon; the solid curve denotes the incorporation of the Norit BRX carbon particles, impregnated with $20 \mathrm{wt} \% \mathrm{FePc}$. The dashed curve was obtained with the latter electrode after saturation of the electrolyte with oxygen and at a rotation frequency of $9 \mathrm{~s}^{-1}$. It is clear that oxygen is reduced at this electrode, starting at about $800 \mathrm{mV}$ (vs. RHE). When the electrode was not rotated in the oxygen-saturated solution, about the same cyclic voltammogram was obtained as that in the nitrogensaturated solution.

Therefore, the net oxygen reduction current at a certain rotation frequency was taken as the difference between the current at this rotation frequency and the current response of the stagnant electrode.

A gold electrode which is covered only with $600 \mathrm{mC}$ PP does not reduce oxygen, neither does an electrode from which the carbon is removed with a tissue. This proves that the catalysis of the oxygen reduction is caused exclusively by the modified carbon itself.

The results with the four modified Au disc electrodes are presented in Fig. 4, with the resulting ring currents.

It must be noted that Norit BRX itself is a very poor catalyst for the reduction of oxygen; the reduction proceeds to $\mathrm{H}_{2} \mathrm{O}_{2}$ exclusively $(N=0.27)$. Impregnation with $\mathrm{H}_{2} \mathrm{Pc}$ shows no improvement, contrary to the use of $\mathrm{CoPc}$ and $\mathrm{FePc}$, which both give significant catalytic improvement. Clearly, the metal ion is the centre of the electrocatalytic activity. The CoPc modified carbon catalyses the reduction of oxygen to $\mathrm{H}_{2} \mathrm{O}_{2}$. However, the FePc-carbon electrode shows the highest activity; moreover, the reduction also proceeds partly to water.

With respect to the selectivity, this behaviour is the same as that of vacuum evaporated $\mathrm{CoPc}$ and FePc films in alkaline solution $[9,10]$, although the $\mathrm{FePc} / \mathrm{BRX}$ electrode here produces relatively more $\mathrm{H}_{2} \mathrm{O}_{2}$; the activity in alkaline solution is higher. 


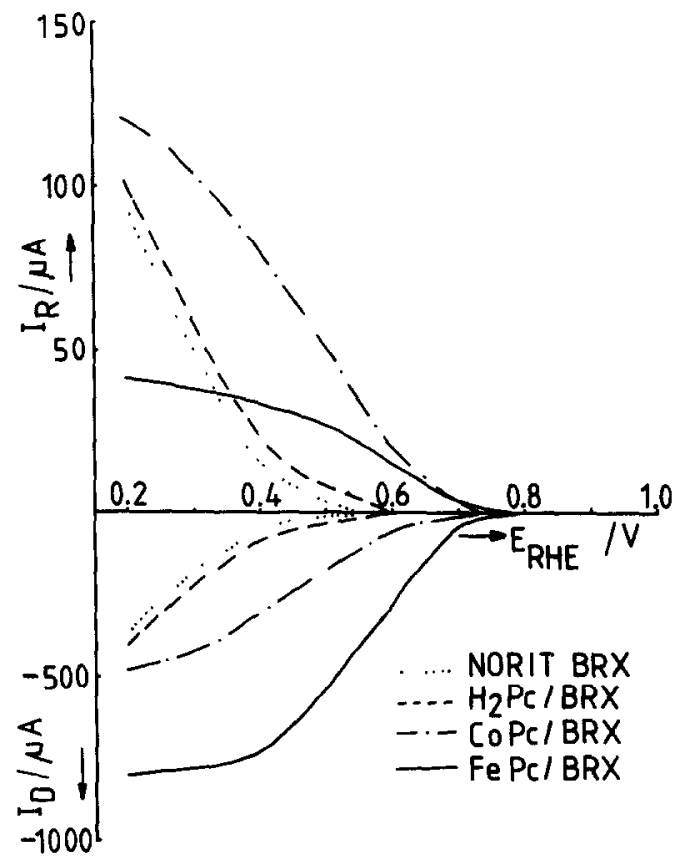

Fig. 4. Oxygen reduction in $0.05 \mathrm{MH}_{2} \mathrm{SO}_{4}$ at $f=9 \mathrm{~s}^{-1}$ at Norit BRX, and at Norit BRX impregnated with $20 \% \mathrm{H}_{2} \mathrm{Pc}$, CoPc and $\mathrm{FePc}$, respectively.

Comparison of our results with those of Van Veen and Visser [8] for gas diffusion electrodes prepared from the same carbons show a similar increase in activity due to impregnation of the Norit BRX.

The fact that the electrodes are not totally covered with carbon is also reflected in the values of the limiting currents. In the case of $\mathrm{CoPc}$, where the reduction proceeds entirely to $\mathrm{H}_{2} \mathrm{O}_{2}$; the theoretical value of this current is $750 \mu \mathrm{A}\left(S=0.5 \mathrm{~cm}^{2}\right.$, $D=2.1 \times 10^{-5} \mathrm{~cm}^{2} \mathrm{~s}^{-1}$ [11], $\nu=10^{-2} \mathrm{~cm} \mathrm{~s}^{-1}$ [12], $c_{\mathrm{O}_{2}}=1.03 \times 10^{-3} M$ [13]. This means that about two thirds of the electrode is covered. It was observed that this fraction is determined mainly by the interaction between the separate particles which will depend on their properties, such as average particle size, surface charge, etc.

\section{CONCLUDING REMARKS}

The catalytic properties of carbon supported catalysts in acidic solution can be measured by incorporation of carbon particles in a polypyrrole film. The transport of reactants to the electrode is much better defined than in the case of gas diffusion electrodes. The preparation of these- electrodes is fast and easy, in contrast to the preparation of gas diffusion electrodes. The selectivity can also be determined since a RRDE can be prepared. Because the formation of the polymer is an electrochem- 
ical process, it is very easy to cover only the disc of the RRDE with the catalyst. All kinds of carbons can be investigated: impregnated with different catalysts or subjected to other treatments, such as pyrolysis. A study to elucidate the effect of pyrolysis on carbon supported transition-metal chelates is currently in progress.

\section{REFERENCES}

1 H. Jahnke, M. Schönborn and G. Zimmermann, Topics Current Chem., 61 (1976) 133.

2 J.A.R. van Veen, Electrochim. Acta, 27 (1982) 1403.

3 M. Savy, P. Andro and C. Bernard, Electrochim. Acta, 19 (1974) 403.

4 L.J.J. Janssen and A.M.T.P. van der Putten, Neth. Patent No. 8500335 (1985).

5 A.F. Diaz, J.I. Castillo, J.A. Logan and W.-Y. Lee, J. Electroanal. Chem. 129 (1981) 115.

6 A.F. Diaz and J.I. Castillo, J. Chem. Soc., Chem. Commun., (1980) 397.

7 V.G. Levich, Physicochemical Hydrodynamics, Prentice-Hall, Englewood Cliffs, NJ, 1962.

8 J.A.R. van Veen and C. Visser, Electrochim. Acta, 24 (1979) 921.

9 F. van den Brink, W. Visscher and E. Barendrecht, J. Electroanal. Chem., 157 (1983) 283.

10 F. van den Brink, W. Visscher and E. Barendrecht, J. Electroanal. Chem., 172 (1984) 301.

11 R.J. Millington, Science, 122 (1955) 1090.

12 R.C. Weast (Ed.), Handbook of Chemistry and Physics, CRC Press, Boca Raton, FA, 62nd ed., 1981-1982, p. D-242.

13 K.E. Gubbins and R.D. Walker, J. Electrochem. Soc., 112 (1965) 469. 